Article

\title{
Glycerolipid Composition of the Red Macroalga Agarophyton Chilensis and Comparison to the Closely Related Agarophyton Vermiculophyllum Producing Different Types of Eicosanoids ${ }^{\dagger}$
}

\author{
Masaki Honda ${ }^{1, *(1)}$, Takashi Ishimaru ${ }^{2}$, Yutaka Itabashi ${ }^{2,3, *}$ and Mikhail Vyssotski ${ }^{4}$ \\ 1 Faculty of Science \& Technology, Meijo University, Shiogamaguchi, Tempaku-ku, Nagoya 468-8502, Japan \\ 2 Faculty of Fisheries Sciences, Hokkaido University, Minato-cho, Hakodate 041-0811, Japan; \\ ishimaru_takashi@kaken.co.jp \\ 3 National Research Institute of Fisheries Science, Japan Fisheries Research and Education Agency, \\ Yokohama 236-8648, Japan \\ 4 Callaghan Innovation, 69 Gracefield Road, P.O. Box 31310, Lower Hutt 5040, New Zealand; \\ mikhail.vyssotski@callaghaninnovation.govt.nz \\ * Correspondence: honda@meijo-u.ac.jp (M.H.); yutaka@fish.hokudai.ac.jp (Y.I.); Tel.: +81-52-838-2284 (M.H.); \\ $+81-45-788-7615$ (Y.I.) \\ + This study was carried out in Hokkaido University, Minato-cho, Hakodate 041-0811, Japan.
}

Received: 25 December 2018; Accepted: 29 January 2019; Published: 2 February 2019

\begin{abstract}
The red macroalga Agarophyton chilensis is a well-known producer of eicosanoids such as hydroxyeicosatetraenoic acids, but the alga produces almost no prostaglandins, unlike the closely related A. vermiculophyllum. This indicates that the related two algae would have different enzyme systems or substrate composition. To carry out more in-depth discussions on the metabolic pathway of eicosanoids between the two algae, we investigated the characteristics of glycerolipids, which are the substrates of eicosanoids production, of A. chilensis and compared them to the reported values of A. vermiculophyllum. In A. chilensis, monogalactosyldiacylglycerol (MGDG), digalactosyldiacylglycerol (DGDG), sulfoquinovosyldiacylglycerol (SQDG), and phosphatidylcholine (PC) were the major lipid classes and accounted for $44.4 \%$ of the total lipid extract. The predominant fatty acids were arachidonic acid (20:4n-6), an eicosanoids precursor, and palmitic acid (16:0). The 20:4n-6 content was extremely high in MGDG and PC (>70\%), and the 16:0 content was extremely high in DGDG and SQDG $(>40 \%)$. A chiral-phase HPLC analysis showed that fatty acids were esterified at the $s n-1$ and $s n-2$ positions of those lipids. The glycerolipid molecular species were determined by reversed-phase HPLC-ESI-MS analysis. The main glycerolipid molecular species were 20:4n-6/20:4n-6 (sn-1/sn-2) for MGDG (63.8\%) and PC (48.2\%), 20:4n-6/16:0 for DGDG (71.1\%) and SQDG $(29.4 \%)$. These lipid characteristics of $A$. chilensis were almost the same as those of $A$. vermiculophyllum. Hence, the differences of the eicosanoids producing ability between the two algae would not be due to the difference of substrate composition but the difference of enzyme system.
\end{abstract}

Keywords: Agarophyton chilensis; Agarophyton vermiculophyllum; lipid class; fatty acid; glycerolipid molecular species; arachidonic acid cascade

\section{Introduction}

Red algae are rich in polyunsaturated fatty acids (PUFA) such as arachidonic acid (20:4n-6) and eicosapentaenoic acid (20:5n-3), which are precursors of eicosanoids. The red macroalga Agarophyton chilensis (C.J.Bird, McLachlan et E.C.Oliveira) Gurgel, J.N.Norris et Fredericq (= Gracilaria chilensis) [1], 
which is native along Southern Hemispheric coastal regions including Chile and New Zealand, is an important marine resource in the production of agar [2-4]. Since the alga can be easily planted and harvested, this crop is exploited by the local population widely along the Chilean coast [4]. A. chilensis is a well-known producer of hydroxylated and dihydroxylated fatty acids derived from 20:4n-6, such as 8-hydroxyeicosatetraenoic acid (8-HETE) and 7,8-dihydroxyeicosatetraenoic acid (7,8-diHETE) for chemical defense against epiphytes $[4,5]$. On the other hand, the closely related A. vermiculophyllum (Ohmi) Gurgel, J.N.Norris et Fredericq (= G. vermiculophylla) [1] produces prostaglandins from 20:4n-6, such as PGE 2 and PGF $_{2 \alpha}$, in addition to 8-HETE and 7,8-diHETE [4,6-10] (Figure 1), which indicates that those algae would have different enzyme systems or substrate composition in spite of related species. Algal eicosanoids are produced from glycerolipid substrates glyceroglycolipids and phospholipids (PC), which are hydrolyzed by acyl-hydrolases that are activated by physical wounding $[4,7,11,12]$. The wounding releases 20:4n-6 or 20:5n-3, which are then transformed to eicosanoids by various enzymes (e.g., lipoxygenases, which are deeply relevant to 8-HETE and 7,8-diHETE production [4,5]; and cyclooxygenases, which are deeply relevant to prostaglandins production [12,13]). Ample studies have investigated the arachidonate metabolites and found their different compositions among Gracilariales (Rhodophyta) to date [4-8], but few studies have focused on the details of the substrates glyceroglycolipids and phospholipids. Therefore, to discuss the differences of the arachidonic acid cascade among Gracilariales, a critical analysis of the substrates is important. Very recently, we reported lipid characteristics of $A$. vermiculophyllum [14]. In the present study, to carry out more in-depth discussions on the metabolic pathway of eicosanoids among Gracilariales, lipid characteristics of $A$. chilensis were investigate and compared with those of A. vermiculophyllum [14], which biosynthesizes the different arachidonate metabolites [4]. Namely, lipid classes, fatty acid composition, and glycerolipid molecular species of $A$. chilensis were clarified using gas chromatography (GC), high-performance liquid chromatography (HPLC), and mass spectrometry (MS), and compared with those of A. vermiculophyllum obtained from our previous study [14].

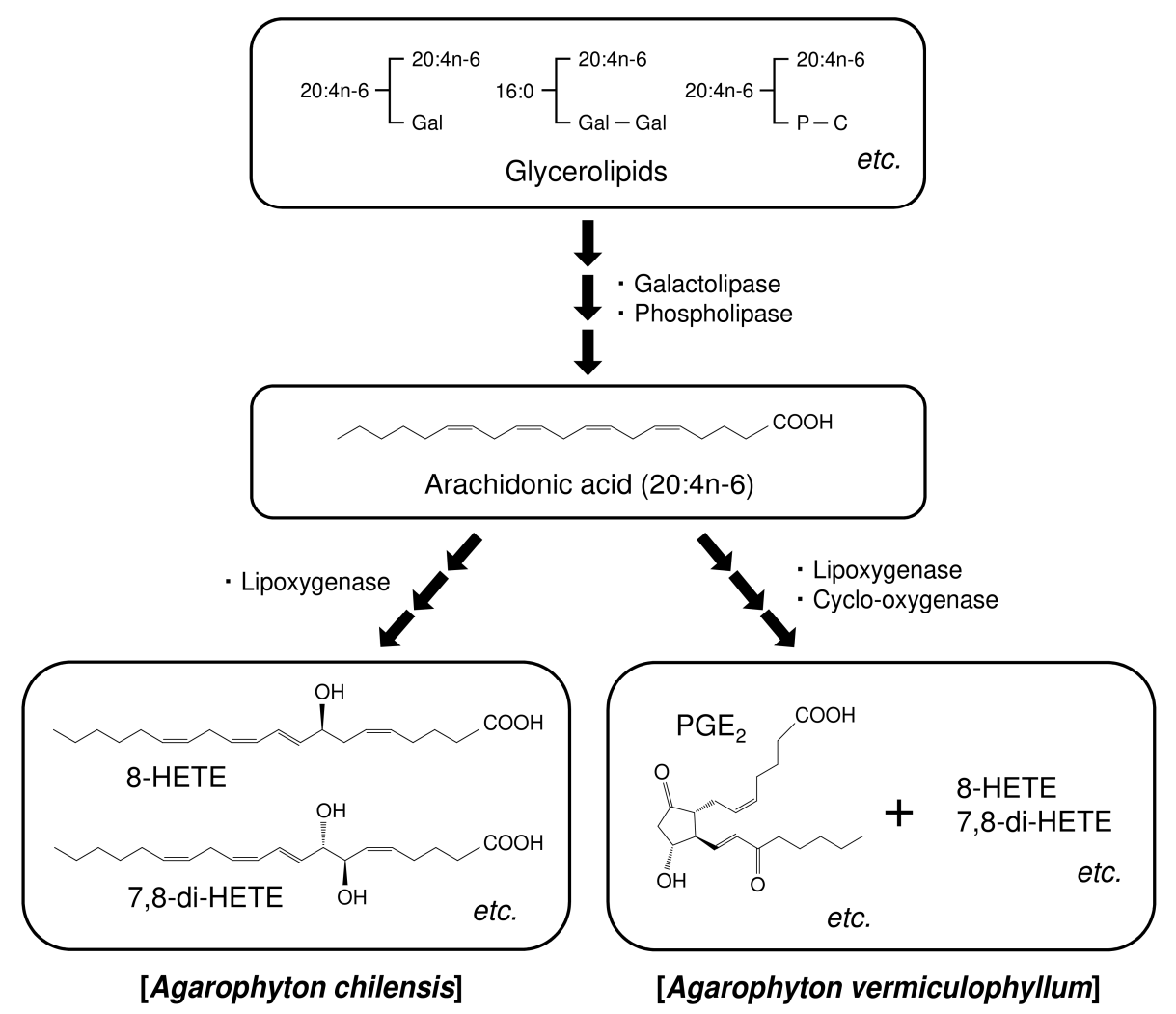

Figure 1. Prospective schematic diagram of arachidonic acid cascade of Agarophyton chilensis and Agarophyton vermiculophyllum [4,6-13]. 


\section{Results and Discussion}

\subsection{Lipid Class Composition}

The HPLC-evaporative light-scattering detection (ELSD) analysis clearly showed that A. chilensis contained three glyceroglycolipids-monogalactosyldiacylglycerol (MGDG), digalactosyldiacylglycerol (DGDG), and sulfoquinovosyldiacylglycerol (SQDG)—and a phospholipid (PC), as well as some lipids such as acyl steryl glycosides (ASG) and sterols (ST) (Figure 2). Those glycerolipids were also found in other Gracilariale (e.g., A. vermiculophyllum, G. textorii, and G. gigas [14-16]). Da Costa et al. [17]. reported that some minor phospholipids such as phosphatidylinositol (PI) and phosphatidylethanolamine (PE) were detected from Gracilariales using MS analysis. Those phospholipids could not be detected in this study, probably because of the dynamic range and limited sensitivity of the ELSD detector [18]. Quantitative estimations of the glycerolipids (MGDG, DGDG, SQGD, and PC) were carried out by HPLC-ELSD using a calibration curve for each glycerolipid [14]. The sum of the four glycerolipids of $A$. chilensis accounted for $44.4 \%$ of the total lipid extract, the contents of which ( $\mathrm{mg} / \mathrm{g}$ of total lipids $\pm \mathrm{SD}$ of three analyses) were higher in the order of DGDG $(142.2 \pm 2.9 \mathrm{mg} / \mathrm{g})>$ SQDG $(130.8 \pm 6.1 \mathrm{mg} / \mathrm{g})>$ PC $(104.5 \pm 3.6 \mathrm{mg} / \mathrm{g})>$ MGDG $(66.5 \pm 2.7 \mathrm{mg} / \mathrm{g})$ (Table 1). A similar order had been observed in A. vermiculophyllum in our previous report [14]: DGDG $(123.7 \pm 2.9 \mathrm{mg} / \mathrm{g})>\mathrm{PC}(110.7 \pm 8.9 \mathrm{mg} / \mathrm{g}) \approx \mathrm{SQDG}(107.8 \pm 5.8 \mathrm{mg} / \mathrm{g})>\mathrm{MGDG}$ $(88.1 \pm 1.2 \mathrm{mg} / \mathrm{g})$. On the other hand, the composition ratio can change in some degree depending on geographical factors and the season [19]. Some other Gracilariales had different glycerolipid compositions (e.g., in G. bursa-pastoris and G. chorda, MGDG was the most predominant glycerolipid, and in G. textorii and G. gigas, PC was the richest one [15]). The results obtained in this study indicated that MGDG, DGDG, SQGD, and PC would become the main substrates of eicosanoids production in A. chilensis as well as A. vermiculophyllum [14].

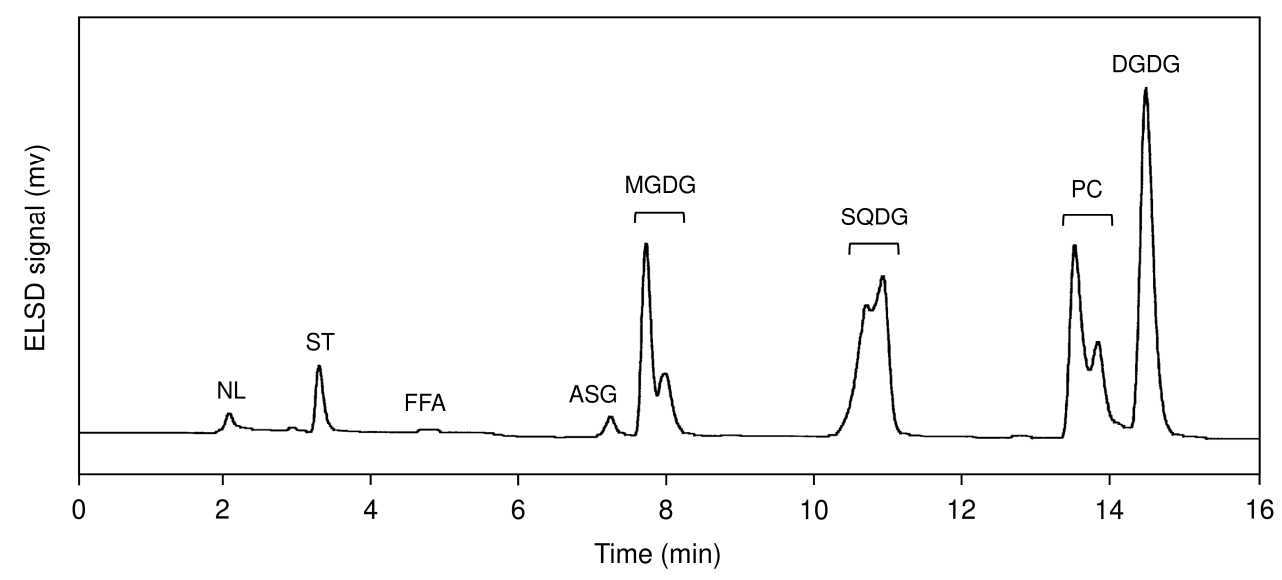

Figure 2. HPLC-ELSD chromatogram of total lipids from Agarophyton chilensis. Peaks were identified by comparison of retention times with those of standard lipids. NL, neutral lipid; ST, sterol; FFA, free fatty acid; ASG, acyl steryl glycoside.

Table 1. Major glycerolipid composition (mg/g of total lipids \pm SD of three analyses) of the red algae Agarophyton chilensis and Agarophyton vermiculophyllum as determined by HPLC-evaporative light-scattering detection (ELSD).

\begin{tabular}{cccccc}
\hline Species & MGDG & DGDG & SQDG & PC & Total \\
\hline A. chilensis & $66.5 \pm 2.7^{\mathrm{d}}$ & $142.2 \pm 2.9^{\mathrm{a}}$ & $130.8 \pm 6.1^{\mathrm{b}}$ & $104.5 \pm 3.6^{\mathrm{c}}$ & 444.0 \\
A. vermiculophyllum & $88.1 \pm 1.2$ & $123.7 \pm 2.9$ & $107.8 \pm 5.8$ & $110.7 \pm 8.9$ & 430.3 \\
\hline
\end{tabular}

${ }^{a-d}$ Means in the same raw with different superscripts significantly differ (Tukey's test, $\left.p<0.05\right)$. ${ }^{*}$ Values are obtained from the literature [14]. MGDG, monogalactosyldiacylglycerol; SQDG, sulfoquinovosyldiacylglycerol; PC, phosphatidylcholine; DGDG, digalactosyldiacylglycerol. 


\subsection{Fatty Acid Composition of Glycerolipids}

Table 2 shows the fatty acid compositions of the glycerolipids from A. chilensis examined in this study and A. vermiculophyllum obtained from our previous report [14]. The main fatty acids of the total lipids in A. chilensis were 16:0 (27.4\%) and 20:4n-6 (58.9\%), as well as in A. vermiculophyllum (Table 2) [14]. Also, in other Gracilariales such as A. tenuistipitatum (= G. tenuistipitata), G. debilis, G. dura, and G. textorii, 16:0 and 20:4n-6 were the major fatty acids $[15,20,21]$. On the other hand, the most predominant fatty acid in G. changgi and G. gigas was 20:5n-3 [15,22]; G. folifera and Hydropuntia edulis (= G. edulis) contained almost no PUFAs [23]. The characteristics of fatty acid composition depended on each major glycerolipid (MGDG, DGDG, SQDG, and PC) of A. chilensis. The 20:4n-6 content was especially high $(>60 \%)$ in MGDG and PC, and the 16:0 content was especially high $(>50 \%)$ in DGDG and SQDG. PC contained a large amount of PUFAs $(76.6 \%)$, whereas SQDG was rich in saturated fatty acids (65.4\%). A similar composition was also observed in A. vermiculophyllum [14] and G. chorda [15]. These results suggest that MGDG and PC rich in 20:4n- 6 would become the main substrates of eicosanoids production in A. chilensis and A. vermiculophyllum.

Table 2. Fatty acid composition (wt\%) of the red algae Agarophyton chilensis and Agarophyton vermiculophyllum.

\begin{tabular}{|c|c|c|c|c|c|c|c|c|c|c|}
\hline \multirow{3}{*}{ Fatty Acid } & \multicolumn{5}{|c|}{ A. Chilensis } & \multicolumn{5}{|c|}{ A. Vermiculophyllum * } \\
\hline & \multirow{2}{*}{ Total Lipid } & \multicolumn{4}{|c|}{ Lipid Class } & \multirow{2}{*}{ Total Lipid } & \multicolumn{4}{|c|}{ Lipid Class } \\
\hline & & MGDG & DGDG & SQDG & PC & & MGDG & DGDG & SQDG & PC \\
\hline $12: 0$ & 0.3 & $\operatorname{tr}$ & $\operatorname{tr}$ & 0.2 & nd & 0.3 & 0.1 & 0.2 & 1.1 & $\operatorname{tr}$ \\
\hline $14: 0$ & 3.6 & 0.4 & 0.8 & 10.9 & 0.9 & 5.3 & 1.7 & 1.8 & 14.7 & 1.2 \\
\hline $15: 0$ & 0.2 & 0.1 & 0.3 & 0.5 & 0.1 & 0.6 & 1.1 & 0.8 & 1.0 & 0.2 \\
\hline $16: 0$ & 27.4 & 12.5 & 43.8 & 52.6 & 15.2 & 31.6 & 21.7 & 54.0 & 61.7 & 15.3 \\
\hline iso $17: 0$ & 0.2 & nd & nd & 0.2 & nd & 0.6 & nd & nd & nd & nd \\
\hline 17:0 & $\operatorname{tr}$ & nd & nd & nd & 0.2 & 0.4 & 1.1 & 0.3 & 0.2 & 0.2 \\
\hline $18: 0$ & 0.5 & 0.4 & 0.6 & 0.8 & 0.7 & 0.7 & 0.5 & 0.4 & 0.4 & 0.7 \\
\hline $22: 0$ & $\operatorname{tr}$ & 0.1 & 0.2 & 0.2 & nd & 0.1 & nd & nd & nd & nd \\
\hline$\Sigma$ Saturated & 32.2 & 13.5 & 45.7 & 65.4 & 17.1 & 39.6 & 26.2 & 57.5 & 79.1 & 17.6 \\
\hline $16: 1 n-9$ & 0.2 & $\operatorname{tr}$ & $\operatorname{tr}$ & 0.2 & nd & 3.7 & 1.5 & 0.7 & 1.3 & $\operatorname{tr}$ \\
\hline $16: 1 n-7$ & 0.1 & nd & nd & 0.9 & 0.2 & $\operatorname{tr}$ & nd & nd & nd & 0.7 \\
\hline $18: 1 n-9$ & 4.3 & 3.9 & 6.6 & 0.1 & 2.4 & 3.3 & 3.2 & 3.8 & 0.8 & 2.1 \\
\hline $18: 1 n-7$ & 1.5 & 0.3 & 0.2 & $\operatorname{tr}$ & 3.0 & 1.7 & 0.5 & 0.2 & 0.3 & 3.2 \\
\hline $20: 1 n-9$ & 0.1 & 0.1 & $\operatorname{tr}$ & nd & 0.1 & 0.2 & 0.2 & $\operatorname{tr}$ & $\operatorname{tr}$ & nd \\
\hline $24: 1 n-9$ & 0.2 & 0.2 & 0.1 & 0.2 & nd & $\operatorname{tr}$ & nd & nd & nd & nd \\
\hline$\Sigma$ Monounsaturated & 6.4 & 4.5 & 6.9 & 1.4 & 5.7 & 8.9 & 5.3 & 4.7 & 2.4 & 6.0 \\
\hline $16: 3 n-3$ & nd & nd & nd & nd & nd & 0.2 & 0.9 & $\operatorname{tr}$ & nd & nd \\
\hline $16: 4 n-3$ & $\operatorname{tr}$ & nd & nd & nd & nd & 0.2 & 0.7 & nd & nd & $\operatorname{tr}$ \\
\hline $18: 2 n-6$ & 0.4 & 0.2 & 0.3 & 0.1 & 1.2 & 0.8 & 0.4 & 0.5 & 0.2 & 0.9 \\
\hline $18: 3 n-6$ & 0.1 & $\operatorname{tr}$ & $\operatorname{tr}$ & $\operatorname{tr}$ & 0.8 & 0.4 & 0.1 & $\operatorname{tr}$ & $\operatorname{tr}$ & 1.1 \\
\hline $18: 3 n-3$ & $\operatorname{tr}$ & nd & nd & nd & 0.3 & 0.3 & 0.4 & 0.2 & 0.1 & 0.1 \\
\hline $18: 4 n-3$ & nd & nd & nd & nd & nd & 0.4 & 1.0 & 0.2 & nd & 0.2 \\
\hline $20: 2 n-6$ & 0.2 & 0.1 & 0.2 & $\operatorname{tr}$ & 0.1 & 0.2 & 0.2 & 0.2 & nd & 0.2 \\
\hline $20: 3 n-6$ & 0.5 & 0.2 & 0.2 & $\operatorname{tr}$ & 1.0 & 2.0 & 0.8 & 0.6 & 0.3 & 5.5 \\
\hline $20: 4 n-6$ & 58.9 & 80.5 & 46.0 & 32.3 & 72.7 & 44.6 & 63.4 & 35.2 & 17.2 & 63.8 \\
\hline $20: 5 n-3$ & 0.4 & 0.6 & 0.2 & $\operatorname{tr}$ & 0.4 & 1.7 & 1.6 & 0.5 & $\operatorname{tr}$ & 2.3 \\
\hline $22: 4 n-6$ & $\operatorname{tr}$ & nd & nd & nd & 0.2 & 0.2 & $\operatorname{tr}$ & nd & nd & 0.5 \\
\hline$\Sigma$ Polyunsaturated & 60.5 & 81.6 & 46.9 & 32.4 & 76.7 & 51.0 & 68.1 & 37.4 & 17.8 & 74.6 \\
\hline Others & 0.9 & 0.4 & 0.5 & 0.8 & 0.5 & 0.5 & 0.4 & 0.4 & 0.7 & 1.8 \\
\hline
\end{tabular}

* Values are obtained from the literature [14]. tr: trace $(<0.1 \%)$. nd: not detected substantially.

\subsection{Positional Isomers of Glycerolipids}

Generally, in higher plants such as spinach and Arabidopsis, the glycerol moieties of glycerolipid have the $S$ configuration [24], as well as in algae such as A. vermiculophyllum [14] and Sargassum yezoense [25]. In this study, the binding position of fatty acids with the glycerol moieties was determined using chiral-phase HPLC. The chiral-phase HPLC chromatograms of 3,5-dinitrophenylurethane (3,5-DNPU) derivatives prepared from the $s n$-1,2(2,3)-diacylglycerols (DAG) standard derived from tuna orbital oil triacylglycerols (TAG) and the DAG released from MGDG, DGDG, SQDG, and PC of A. chilensis are shown in Supplementary Figure S1. The standard was clearly separated into two groups, representing the $s n-1,2$ - and $s n-2,3$-enantiomers (Supplementary Figure 
S1A): The faster elution group consisted of $s n$-1,2-enantiomers, and the subsequent group consisted of sn-2,3-enantiomers on the A-K03 column [14,25-27]. Since the presence of various molecular species in tuna orbital oil TAG, each enantiomeric group was split. All DAG released from MGDG, DGDG, SQDG, and PC of $A$. chilensis were eluted within $20 \mathrm{~min}$, and the enantiomeric group was also split because of the presence of various molecular species (Supplementary Figure S1B-E). Thus, in A. chilensis, fatty acids were esterified at the $s n-1$ and $s n-2$ positions ( $S$ configuration) of those glycerolipids as with higher plants [24] and A. vermiculophyllum [14].

\subsection{Molecular Species of Glycerolipids}

Figure 3 shows the reversed-phase HPLC chromatograms of 3.5-DNPU derivatives and Table 3 shows the molecular species composition of the glycerolipids from $A$. chilensis examined in this study and $A$. vermiculophyllum obtained from our previous report [14].

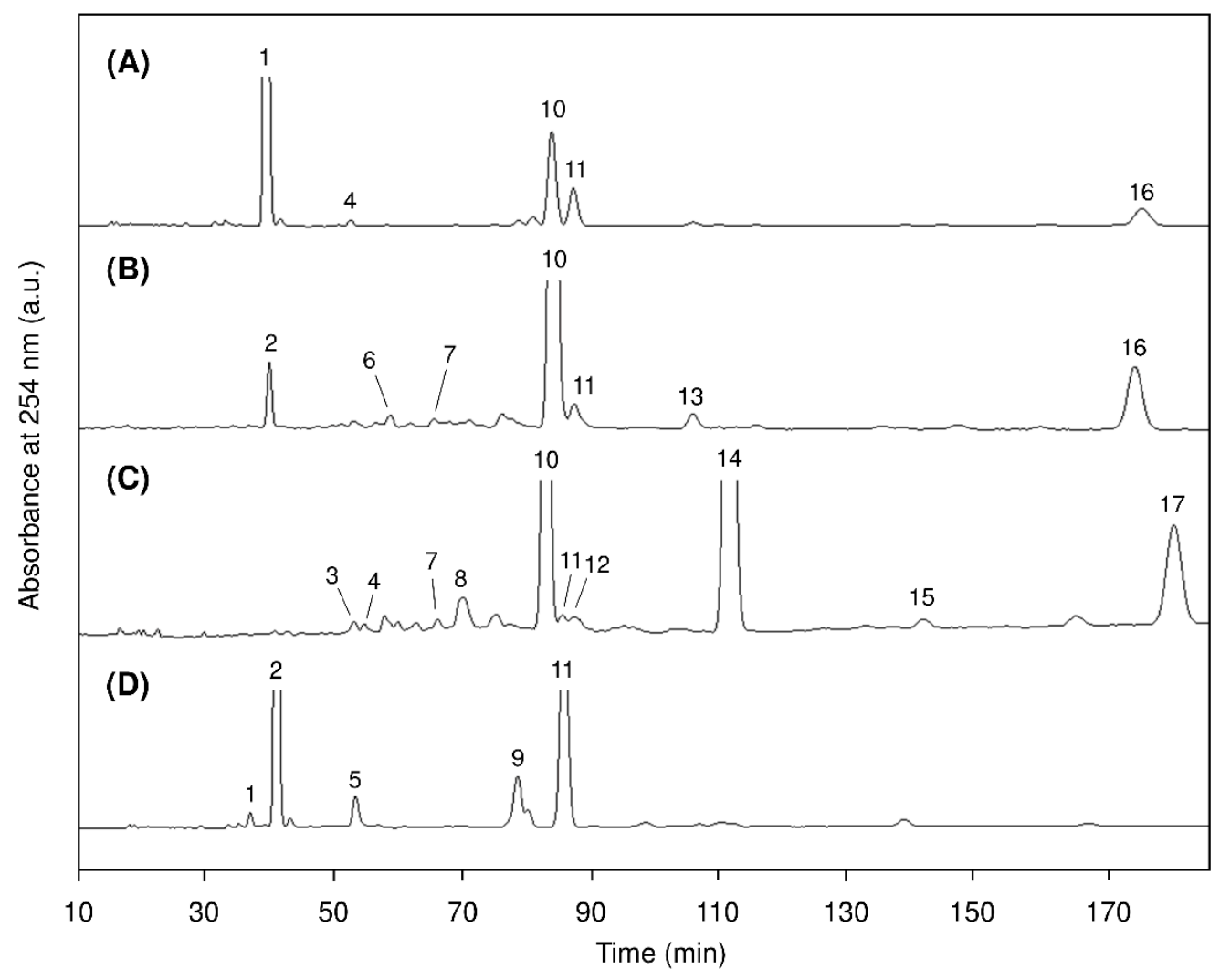

Figure 3. Reversed-phase HPLC chromatograms of the 3,5-DNPU derivatives of diacylglycerols released from (A) MGDG, (B) DGDG, (C) SQDG, and (D) PC of Agarophyton chilensis. Peak numbers corresponding to those in Table 3. 
Table 3. Molecular species composition (mol\%) of the red algae Agarophyton chilensis and Agarophyton vermiculophyllum.

\begin{tabular}{|c|c|c|c|c|c|c|c|c|c|c|}
\hline \multirow{2}{*}{ Peak No * } & \multirow{2}{*}{$\mathrm{ECN} * *$} & \multirow{2}{*}{$\begin{array}{c}\text { Molecular Species } \\
(s n-1 / s n-2)\end{array}$} & \multicolumn{4}{|c|}{ A. Chilensis } & \multicolumn{4}{|c|}{ A. Vermiculophyllum *** } \\
\hline & & & MGDG & DGDG & SQDG & PC & MGDG & DGDG & SQDG & PC \\
\hline- & 18 & $20: 5 n-3 / 16: 4 n-3$ & nd & nd & nd & nd & 2.0 & nd & nd & nd \\
\hline- & 20 & $18: 4 n-3 / 18: 4 n-3$ & nd & nd & nd & nd & 1.0 & nd & nd & nd \\
\hline- & 20 & $20: 5 n-3 / 16: 3 n-3$ & nd & nd & nd & nd & 0.8 & nd & nd & nd \\
\hline- & 20 & $20: 5 n-3 / 18: 4 n-3$ & nd & nd & nd & nd & 0.9 & 1.1 & nd & nd \\
\hline- & 22 & $16: 2 n-6 / 16: 3 n-3$ & nd & nd & nd & nd & 0.8 & nd & nd & nd \\
\hline- & 22 & $20: 4 n-6 / 20: 5 n-3$ & nd & nd & nd & nd & 1.0 & nd & nd & nd \\
\hline- & 22 & $20: 5 n-3 / 16: 2 n-6$ & nd & nd & nd & nd & nd & 0.5 & nd & nd \\
\hline- & 24 & 14:0/18:4n-3 & nd & nd & nd & nd & 0.5 & nd & nd & nd \\
\hline - & 24 & $16: 2 n-6 / 16: 2 n-6$ & nd & nd & nd & nd & 0.8 & nd & nd & nd \\
\hline 1 & 24 & $20: 4 n-6 / 18: 3 n-6$ & nd & nd & nd & 1.0 & nd & nd & nd & 1.2 \\
\hline 2 & 24 & $20: 4 n-6 / 20: 4 n-6$ & 63.8 & 4.1 & nd & 48.2 & 56.5 & 7.8 & 0.8 & 40.0 \\
\hline- & 26 & $20: 5 n-3 / 20: 2 n-6$ & nd & nd & nd & nd & nd & nd & nd & 0.9 \\
\hline- & 26 & $18: 2 n-6 / 20: 4 n-6$ & nd & nd & nd & nd & nd & 0.2 & nd & nd \\
\hline 3 & 26 & $20: 4 n-6 / 14: 0$ & nd & nd & 0.4 & nd & nd & 0.4 & 0.3 & nd \\
\hline 4 & 26 & 14:0/20:4n-6 & 0.8 & nd & 0.2 & nd & 1.8 & 1.7 & 0.2 & nd \\
\hline 5 & 26 & $20: 4 n-6 / 20: 3 n-6$ & nd & nd & nd & 3.2 & nd & nd & nd & 10.2 \\
\hline 6 & 26 & $20: 5 n-3 / 16: 0$ & nd & 0.8 & nd & nd & nd & 0.5 & 0.2 & nd \\
\hline 7 & 27 & $20: 4 n-6 / 15: 0$ & nd & 0.5 & 0.4 & nd & nd & 1.0 & 0.7 & nd \\
\hline- & 27 & $15: 0 / 20: 4 n-6$ & nd & nd & nd & nd & nd & 0.3 & nd & nd \\
\hline 8 & 28 & $12: 0 / 16: 0$ & nd & nd & 2.7 & nd & nd & nd & 3.2 & nd \\
\hline 9 & 28 & $18: 1 n-9 / 20: 4 n-6$ & nd & nd & nd & 7.6 & nd & nd & nd & 7.7 \\
\hline 10 & 28 & $20: 4 n-6 / 16: 0$ & 16.2 & 71.1 & 29.4 & nd & 17.7 & 75.4 & 58.4 & nd \\
\hline 11 & 28 & $16: 0 / 20: 4 n-6$ & 6.7 & 1.8 & 0.3 & 31.3 & 7.3 & 4.3 & 0.2 & 26.3 \\
\hline 12 & 29 & 15:0/14:0 & nd & nd & 0.4 & nd & nd & nd & 0.7 & nd \\
\hline- & 30 & $16: 1 n-9 / 16: 0$ & nd & nd & nd & nd & nd & nd & 1.2 & nd \\
\hline 13 & 30 & $14: 0 / 18: 1 n-9$ & nd & 1.7 & nd & nd & 0.3 & 0.8 & nd & nd \\
\hline- & 30 & $16: 0 / 20: 3 n-6$ & nd & nd & nd & nd & nd & nd & nd & 3.8 \\
\hline 14 & 30 & $14: 0 / 16: 0$ & nd & nd & 49.3 & nd & nd & nd & 29.4 & nd \\
\hline- & 30 & $16: 0 / 20: 3 n-6$ & nd & nd & nd & nd & 0.3 & 0.6 & nd & nd \\
\hline 15 & 31 & $15: 0 / 16: 0$ & nd & nd & 0.3 & nd & nd & nd & nd & nd \\
\hline 16 & 32 & $16: 0 / 18: 1 n-9$ & 5.6 & 13.4 & nd & nd & 2.5 & 3.5 & nd & nd \\
\hline \multirow{2}{*}{17} & 32 & $16: 0 / 16: 0$ & nd & nd & 11.7 & nd & nd & nd & 3.6 & nd \\
\hline & & Others & 6.9 & 6.6 & 4.9 & 8.7 & 5.8 & 1.9 & 1.1 & 9.9 \\
\hline
\end{tabular}

* Peak numbers corresponding to those given in Figure 3. ** Equivalent carbon number (total number of carbon atoms in the two constituent fatty acids $-2 \times$ total number of their double bonds). ${ }^{* * *}$ Values are obtained from the literature [14]. tr: trace $(<0.1 \%)$. nd: not detected substantially.

The quantitative estimation of the glycerolipid molecular species were performed by reversed-phase HPLC with UV detection, and the detected molecular species were determined by reversed-phase HPLC-electrospray ionization (ESI)-MS analysis [14,25]. The 3,5-DNPU derivatives of the DAG released from MGDG, DGDG, SQDG, and PC were eluted in the order of the equivalent carbon number $(\mathrm{ECN}$; total number of carbon atoms in the two constituent fatty acids $-2 \times$ total number of their double bonds) on the reversed-phase HPLC as previously described [14]. Although A. vermiculophyllum contained more kinds of the molecular species than A. chilensis in any glycerolipids, the major molecular species were almost the same between them. Namely, in A. chilensis, the 20:4n-6/20:4n-6 (sn-1/sn-2) species accounted for the largest proportion of MGDG $(63.8 \%)$ and PC $(48.2 \%)$, whereas the 20:4n-6/16:0 species was the predominant species in DGDG $(71.1 \%)$, and the 14:0/16:0 and 20:4n-6/16:0 species mainly presented in SQDG (49.3\% and $29.4 \%$, respectively). A similar molecular species composition was observed in A. vermiculophyllum [14] $-56.5 \%$ and $40.0 \%$ of the 20:4n-6/20:4n-6 species in MGDG and PC, respectively; $75.4 \%$ of the $20: 4 n-6 / 16: 0$ species in DGDG; $49.3 \%$ of the $14: 0 / 16: 0$ and $29.4 \%$ of the 20:4n-6/16:0 in SQGD. MGDG and PC of $A$. chilensis also contained a high proportion of 20:4n-6/16:0 (16.2\%) and 16:0/20:4n-6 (31.3\%), respectively, as with A. vermiculophyllum [14]. The sn-position of 16:0 and 20:4n-6 in MGDG, DGDG, and SQDG was opposite to that of the main molecular species of PC. The 16:0 and 20:4n-6 were mainly esterified at the $s n-1$ and $s n-2$ positions, respectively, in MGDG, DGDG, and SQDG, while 16:0 and 20:4n-6 were esterified at the $s n-2$ and $s n-1$ positions, respectively, in PC. Furthermore, in addition to the 20:4n-6/16:0 species, a small amount of its reverse isomer (16:0/20:4n-6) was present in MGDG, DGDG, and SQDG, whereas PC did not contain the reverse isomer of the 16:0/20:4n-6 species. Such a 
tendency has also been observed in A. vermiculophyllum [14]. The 16:0/20:4n-6 was found in MGDG of two species of red algae, Porphyra yezoensis and Corallina pilulifera, but the species was not found in DGDG and SQDG, nor was the 20:4n-6/16:0 found in the PC of these algal species [28]. The co-existence of both isomers indicates that glycerolipids of $A$. chilensis were biosynthesized from both the prokaryotic pathway (biosynthesized in the chloroplast envelope) and the eukaryotic pathway (biosynthesized in the chloroplast envelope after passing through the endoplasmic reticulum) as described previously [14,29-31].

Lipid composition and glycerolipid molecular species between $A$. chilensis and A. vermiculophyllum were almost the same. These results indicate that the differences of the eicosanoid producing ability do not result from the difference in substrates but from the difference in enzyme systems inherent in the alga body, whereas it cannot be denied that the difference is caused by geographical factors and seasons [8,19]. Therefore, in A. chilensis and A. vermiculophyllum, the first stage reaction of eicosanoids production of the both algae is the hydrolysis of membrane glycerolipids by acyl-hydrolases, which is triggered by physical wounding [4,5], and the 20:4n-6, an eicosanoid precursor, would mainly be released from the MGDG (20:4n-6/20:4n-6 and 20:4n-6/16:0 species), DGDG (20:4n-6/16:0 species), SQDG (20:4n-6/16:0 species), and PC (20:4n-6/20:4n-6 and 16:0/20:4n-6 species).

\section{Materials and Methods}

\subsection{Materials}

The sample of A. chilensis was collected from the coast of Petone, Wellington, New Zealand, in May 2008. The alga was freed from epiphytic organisms and kept at $-20{ }^{\circ} \mathrm{C}$ until use. Analyticaland HPLC-grade solvents, and 1,1-dimethylhydrazine were obtained from Kanto Chemical (Tokyo, Japan). Standard samples of MGDG, DGDG, and SQDG from plant leaves were obtained from Lipid Products (Redhill, United Kingdom), and PC from soybean was obtained from Sigma-Aldrich (St. Louis, MO, USA). 3,5-Dinitrophenyl isocyanate was purchased from Sumika Chemical Analysis Service (Osaka, Japan).

\subsection{Lipid Extraction}

The Bligh-Dyer method [32] was used to extract lipid from A. chilensis. In brief, $96.8 \mathrm{~g}$ of the algal sample was homogenized with $200 \mathrm{~mL}$ of methanol and $100 \mathrm{~mL}$ of chloroform $\left(\mathrm{CH}_{3} \mathrm{Cl}\right)$. After filtration, $100 \mathrm{~mL}$ of $\mathrm{CH}_{3} \mathrm{Cl}$ and $100 \mathrm{~mL}$ of water were added to the algal residue, homogenized, and filtered. Subsequently, $200 \mathrm{~mL}$ of $\mathrm{CH}_{3} \mathrm{Cl}$ was added to the residue, separated in the same manner, and then all the obtained solvent fractions were mixed. After being left standing for $12 \mathrm{~h}$ in the dark at room temperature, the organic solvent layer (lower layer) was collected, the solvent was evaporated to dryness under reduced pressure, and consequently $619 \mathrm{mg}$ of lipid extract was obtained.

\subsection{Lipid Class Analysis}

The quantitative analysis of the major glycerolipids (MGDG, DGDG, SQDG, and PC) was performed by HPLC-ELSD according to the method described previously [14,33,34]. In brief, glycerolipids were separated with a LiChrospher 100 DIOL column $(250 \times 4.0 \mathrm{~mm}$ i.d., $5 \mu \mathrm{m}$ particles, Merck, Darmstadt, Germany) using two mobile phases consisting of (A) $\mathrm{CH}_{3} \mathrm{Cl}$ and (B) methanol/acetone/water/acetic acid (30:60:9:1, $v / v / v / v)$. The gradient profile was as follows: 0-1 $\mathrm{min}, 0 \%$ (B); 1-2 min, 0-30\% (B) linear; $2-6 \mathrm{~min}, 30 \%$ (B); 6-8 $\mathrm{min}, 30-50 \%$ (B) linear; $8-13 \mathrm{~min}$, $50 \%$ (B); $13-15 \mathrm{~min}, 50-100 \%$ (B) linear; $15-16 \mathrm{~min}, 100 \%$ (B). The other analytical conditions were as following: Flow rate of $0.9 \mathrm{~mL} / \mathrm{min}$; column temperature of $35^{\circ} \mathrm{C}$; detector (SEDEX model 55; SEDERE, Alfortville, France) temperature of $50{ }^{\circ} \mathrm{C}$; nebulizer pressure (air) of $250 \mathrm{kPa}$. Peaks were identified by comparing retention times with those of standard lipids, and standard curves were prepared for MGDG, DGDG, SQDG, and PC quantifications. 


\subsection{Isolation of Glycerolipids}

The major glycerolipids (MGDG, DGDG, SQDG, and PC) were separated from the total lipids of $A$. chilensis by thin-layer chromatography (TLC) on silica gel $60 \mathrm{~F}_{254}$ glass sheets $(20 \times 20 \mathrm{~cm}$, $0.25 \mathrm{~mm}$ thick, Merck, Darmstadt, Germany), using $\mathrm{CH}_{3} \mathrm{Cl} /$ methanol/water/ethyl acetate/2-propanol (5:2:1:5:5, $v / v / v / v / v)$ as the developing solvent [14]. SQDG was further purified by TLC, with a solvent system of $\mathrm{CH}_{3} \mathrm{Cl} /$ acetone/methanol/water/acetic acid (10:6:2:1:2, $\left.v / v / v / v / v\right)$.

\subsection{Fatty Acid Analysis}

The fatty acids in the isolated glycerolipids (MGDG, DGDG, SQDG, and PC) were methylated to fatty acid methyl esters (FAME) by heating at $90{ }^{\circ} \mathrm{C}$ for $1 \mathrm{~h}$ in $5 \%(w / v) \mathrm{HCl}$ in methanol [35]. Gas chromatography analysis of the FAME was performed using a Shimadzu GC-14A (Shimadzu, Kyoto, Japan) equipped with a flame-ionization detector and an Omegawax 320 column ( $30 \mathrm{~m} \times 0.32 \mathrm{~mm}$ i.d., Supelco, Bellefonte, PA, USA) $[10,14]$. The column temperature was elevated from 170 to $230{ }^{\circ} \mathrm{C}$ at $1{ }^{\circ} \mathrm{C} / \mathrm{min}$ and the other conditions were as following: injector temperature, $230{ }^{\circ} \mathrm{C}$; detector temperature, $230{ }^{\circ} \mathrm{C}$; carrier gas, helium (linear flow $1.2 \mathrm{~mL} / \mathrm{min}$ ); split ratio, 1:50. Peaks were monitored on a Shimadzu Chromatopac C-R6A integrator and identified by comparing the retention data of authentic standards and known fatty acids from marine algae [14,36].

\subsection{Release of DAG from Glycerolipids}

The isolated glycerolipids (MGDG, DGDG, SQDG, and PC) were converted into DAG as described by Heinze et al. [37]. In detail, $2 \mathrm{mg}$ of glycoglycerolipid and $52 \mathrm{mg}$ of $\mathrm{HIO}_{4} \cdot 4 \mathrm{H}_{2} \mathrm{O}$ were dissolved in $1 \mathrm{~mL}$ of methanol and placed in the dark at room temperature for $90 \mathrm{~min}$. Subsequently, $4 \mathrm{~mL}$ of $\mathrm{CH}_{3} \mathrm{Cl}$ and $2.5 \mathrm{~mL}$ of $0.45 \% \mathrm{NaCl}$ solution were added and shaken vigorously. After brief centrifugation, the organic solvent layer (lower layer) was evaporated under nitrogen gas. The residue was dissolved in $0.5 \mathrm{~mL}$ of $\mathrm{CH}_{3} \mathrm{Cl}$ /water/2-propanol/acetic acid (6:7:2:3, v/v/v/v) containing $1 \%$ 1,1-dimethylhydrazine and placed in the dark at $25^{\circ} \mathrm{C}$ for $4 \mathrm{~h}$ for DGDG, and $20 \mathrm{~h}$ for MGDG, SQDG and PC. Then, $3 \mathrm{~mL}$ of hexane was added and the mixture was washed twice with $2 \mathrm{~mL}$ of $50 \mathrm{mM} \mathrm{KH} \mathrm{PO}_{4}$ solution and dried over anhydrous $\mathrm{Na}_{2} \mathrm{SO}_{4}$. The residue containing DAG released from the glycerolipids was obtained after removal of the solvent.

\subsection{Preparation of 3,5-Dinitrophenylurethane Derivatives}

The DAG released from glycerolipids (MGDG, DGDG, SQDG, and PC) were immediately converted into their 3,5-DNPU derivatives as described previously $[14,36]$. By this derivatization, the DAG derivative took on good absorption at $254 \mathrm{~nm}$. The reaction products (DAG) and 3,5-dinitrophenyl isocyanate $(5 \mathrm{mg})$ were dissolved in dry toluene $(5 \mathrm{~mL})$ containing $30 \mu \mathrm{L}$ of dry pyridine, and the solution was kept at $30{ }^{\circ} \mathrm{C}$ for $3 \mathrm{~h}$ with stirring. After removal of the solvent by nitrogen flow, the residue (crude urethane derivatives) were purified by TLC on silica gel $60 \mathrm{~F}_{254}$ glass sheets (Merck, Darmstadt, Germany) with hexane/dichloromethane $\left(\mathrm{CH}_{2} \mathrm{Cl}_{2}\right)$ /ethanol $(40: 10: 3, v / v / v)$ as the developing solvent. Bands were visualized under UV irradiation (Rf: 0.6-0.7), and the adsorbent containing the derivatives was scraped off and extracted with diethyl ether.

\subsection{Chiral-Phase HPLC}

Chiral-phase HPLC analysis was carried out to determine the binding position of fatty acids to the glycerol moieties of the DAG as 3,5-DNPU derivatives [14,25]. The analysis was carried out on a Shimadzu LC-6A instrument equipped with a chiral column (YMC-Pack A-K03, $250 \times 4.6 \mathrm{~mm}$ i.d., $5 \mu \mathrm{m}$ particles, YMC, Kyoto, Japan). The mobile phase consisted of a mixture of hexane $/ \mathrm{CH}_{2} \mathrm{Cl}_{2}$ / ethanol $(40: 10: 1, v / v / v)$ and the detection wavelength of the derivatives was set at $254 \mathrm{~nm}$. The flow rate and column temperature were set at $1 \mathrm{~mL} / \mathrm{min}$ and $10{ }^{\circ} \mathrm{C}$. The chirality of the DAG released from glycerolipids was determined by comparing the retention times of the 3,5-DNPU derivatives with 
those of standard $s n-1,2-$ and $s n-2,3-D A G$ prepared from tuna orbital oil (TAG) by partial Grignard degradation $[14,24]$.

\subsection{Reversed-Phase HPLC}

Molecular species analysis of DAG as 3,5-DNPU derivatives was performed by reversed-phase HPLC according to the method described previously [14,25]. Briefly, the analysis was performed on a Superspher 100 RP-18 column $(250 \times 4.0$ mm i.d., $4 \mu \mathrm{m}$ particles, Merck, Darmstadt, Germany) with acetonitrile at a flow rate of $0.5 \mathrm{~mL} / \mathrm{min}$ and a column temperature was set at $20^{\circ} \mathrm{C}$. The quantification of the 3,5-DNPU derivatives was performed by peak area integration at $254 \mathrm{~nm}$ (L-7455; Hitachi Ltd., Tokyo, Japan).

\subsection{Reversed-Phase HPLC-ESI-MS}

In order to determine the molecular species of DAG as 3,5-DNPU derivatives, reversed-phase HPLC-ESI-MS was carried out in the negative ion mode with an LCQ ion-trap mass spectrometer (Thermo Separation Products, San Jose, CA, USA) [14,25]. Separations of the 3,5-DNPU derivatives were performed under the same conditions as the HPLC analysis with UV detection as mentioned above. The heated capillary temperature was $270{ }^{\circ} \mathrm{C}$. The tube lens offset, capillary voltage, and spray voltage were $-60 \mathrm{~V},-28 \mathrm{~V}$, and $4.2 \mathrm{kV}$, respectively. Flow rates of the nitrogen sheath and auxiliary gases were set to 80 and 30 arbitrary units (arb), respectively. The mass spectra were taken in a mass range of $\mathrm{m} / \mathrm{z} 150-\mathrm{m} / \mathrm{z} 1200$. The deprotonated molecule ion $\left([\mathrm{M}-\mathrm{H}]^{-}\right)$and carboxylate anion $\left([\mathrm{RCOO}]^{-}\right)$were used to identify individual molecular species of glycerolipids. The relative intensities of two carboxylate anions-carboxylate anions generated from the $s n-1$ position $\left(\mathrm{R}^{1} \mathrm{COO}\right)^{-}$, and carboxylate anions from the $s n-2$ position $\left(\mathrm{R}^{2} \mathrm{COO}\right)^{-}$- produced from 3,5-DNPU derivatives of glycerolipids by collision-induced dissociation (CID) were used for determining the sn-position ( $s n-1$ or $s n-2)$ of the acyl groups in the molecules $[14,25,38]$. Namely, the property that the intensities of $\left(\mathrm{R}^{2} \mathrm{COO}\right)^{-}$were higher than those of $\left(\mathrm{R}^{1} \mathrm{COO}\right)^{-}$when $\mathrm{CID}$ energy was added was utilized.

\section{Conclusions}

Lipid class, fatty acid composition, and glycerolipid molecular species of the red alga A. chilensis were investigated and compared with the related A. vermiculophyllum to deepen discussions on the different metabolic pathway of eicosanoids between them. In A. chilensis, MGDG, DGDG, SQDG, and PC were the major lipid classes and 20:4n-6 and 16:0 were the predominant fatty acids in these glycerolipids. The 20:4n-6/20:4n-6 species was predominant in MGDG $(63.8 \%)$ and PC $(48.2 \%)$, the 20:4n-6/16:0 species was predominant in DGDG (71.1\%), and the 14:0/16:0 and 20:4n-6/16:0 species were predominant in SQDG (49.3\% and $29.4 \%$, respectively). The glycerolipids characteristics of A. chilensis were almost the same as those of $A$. vermiculophyllum. Since glycerolipids are a substance of eicosanoids production, the differences of the eicosanoids producing ability between the algae would be due to having the different arachidonic acid cascades. The results of this study should help the elucidation of the eicosanoids production mechanism of the Gracilariales. It is expected that a future study will extend to enzymes such as lipoxygenases and cyclooxygenases and the enzyme genes associated with biosynthesis of the eicosanoids the species.

Supplementary Materials: The following are available online at http:/ /www.mdpi.com/1660-3397/17/2/96/s1, Figure S1: Chiral-phase HPLC chromatograms of the 3,5-DNPU derivatives of (A) standard sn-1,2(2,3)-DAG generated from tuna orbital oil TAG by partial Grignard degradation, and of the diacylglycerols released from (B) MGDG, (C) DGDG, (D) SQDG, and (E) PC of Agarophyton chilensis.

Author Contributions: M.H., Y.I. and M.V. conceived and designed research. M.H., T.I. and Y.I. analyzed and interpreted data. M.H. and T.I. wrote the manuscript. All authors read and approved the final version of the manuscript.

Funding: This work was partly supported by a Grant-in-Aid for Scientific Research from the Japan Society for the Promotion of Science (Grant No. 18380122 to Y.I.). 
Acknowledgments: The authors thank W.N. (NIWA) for identification of the sample species.

Conflicts of Interest: The authors declare no conflict of interest.

\section{References}

1. Gurgel, C.F.D.; Norris, J.N.; Schmidt, W.E.; Le, H.N.; Fredericq, S. Systematics of the Gracilariales (Rhodophyta) including new subfamilies, tribes, subgenera, and two new genera, Agarophyton gen. nov. and Crassa gen. nov.. Phytotaxa 2018, 374, 1-23.

2. Buschmann, A.H.; Briganti, F.; Retamales, C.A. Intertidal cultivation of Gracilaria chilensis (Rhodophyta) in southern Chile: Long term invertebrate abundance patterns. Aquaculture 1997, 156, 269-278. [CrossRef]

3. Byrne, K.; Zuccarello, G.C.; West, J.; Liao, M.L.; Kraft, G.T. Gracilaria species (Gracilariaceae, Rhodophyta) from southeastern Australia, including a new species, Gracilaria perplexa sp. nov.: Morphology, molecular relationships and agar content. Phycol. Res. 2002, 50, 295-311. [CrossRef]

4. Rempt, M.; Weinberger, F.; Grosser, K.; Pohnert, G. Conserved and species-specific oxylipin pathways in the wound-activated chemical defense of the noninvasive red alga Gracilaria chilensis and the invasive Gracilaria vermiculophylla. Beilstein J. Org. Chem. 2012, 8, 283-289. [CrossRef] [PubMed]

5. Lion, U.; Wiesemeier, T.; Weinberger, F.; Beltrán, J.; Flores, V.; Faugeron, S.; Correa, J.; Pohnert, G. Phospholipases and galactolipases trigger oxylipin-mediated wound-activated defence in the red alga Gracilaria chilensis against epiphytes. ChemBioChem 2006, 7, 457-462. [CrossRef] [PubMed]

6. Fusetani, N.; Hashimoto, K. Prostaglandin $\mathrm{E}_{2}$ : A candidate for causative agent of "ogonori" poisoning. Nippon Suisan Gakkaishi 1984, 50, 465-469. [CrossRef]

7. Nakajima, I.; Suzaki, K.; Oba, K. Production of prostaglandins by the marine alga, Gracilaria verrucosa. J. Jpn. Oil Chem. Soc. 1998, 47, 753-758. [CrossRef]

8. Imbs, A.B.; Vologodskaya, A.V.; Nevshupova, N.V.; Khotimchenko, S.V.; Titlyanov, E.A. Response of prostaglandin content in the red alga Gracilaria verrucosa to season and solar irradiance. Phytochemistry 2001, 58, 1067-1072. [CrossRef]

9. Kodama, S.; Nakajima, S.; Ozaki, H.; Takemoto, R.; Itabashi, Y.; Kuksis, A. Enantioseparation of hydroxyeicosatetraenoic acids by hydroxypropyl- $\gamma$-cyclodextrin-modified micellar electrokinetic chromatography. Electrophoresis 2016, 37, 3196-3205. [CrossRef] [PubMed]

10. Jacquemoud, D.; Pohnert, G. Extraction and analysis of oxylipins from macroalgae illustrated on the example Gracilaria vermiculophylla. In Natural Products from Marine Algae; Stengel, D.B., Connan, S., Eds.; Humana Press: New York, NY, USA, 2015; pp. 159-172.

11. Illijas, M.I.; Terasaki, M.; Nakamura, R.; Iijima, N.; Hara, A.; Fusetani, N.; Itabashi, Y. Purification and characterization of glycerolipid acyl-hydrolase from the red alga Gracilaria vermiculophylla. Fish. Sci. 2008, 74, 670-676. [CrossRef]

12. Nakajima, I.; Suzaki, K.; Oba, K. Mechanism for prostaglandin synthesis in the marine alga, Gracilaria verrucosa. J. Jpn. Oil Chem. Soc. 1998, 47, 759-763. [CrossRef]

13. Kanamoto, H.; Takemura, M.; Ohyama, K. Identification of a cyclooxygenase gene from the red alga Gracilaria vermiculophylla and bioconversion of arachidonic acid to $\mathrm{PGF}_{2 \alpha}$ in engineered Escherichia coli. Appl. Microbiol. Biotechnol. 2011, 91, 1121-1129. [CrossRef] [PubMed]

14. Honda, M.; Ishimaru, T.; Itabashi, Y. Lipid classes, fatty acid composition, and glycerolipid molecular species of the red alga Gracilaria vermiculophylla, a prostaglandin-producing seaweed. J. Oleo Sci. 2016, 65, 723-732. [CrossRef] [PubMed]

15. Araki, S.; Sakurai, T.; Oohusa, T.; Kayama, M.; Nisizawa, K. Content of arachidonic and eicosapentaenoic acids in polar lipids from Gracilaria (Gracilariales, Rhodophyta). Hydrobiologia 1990, 204/205, 513-519. [CrossRef]

16. Khotimchenko, S.V. Lipids from the marine alga Gracilaria verrucosa. Chem. Nat. Compd. 2005, 41, $285-288$. [CrossRef]

17. Da Costa, E.; Melo, T.; Moreira, A.S.P.; Bernardo, C.; Helguero, L.; Ferreira, I.; Cruz, M.T.; Rego, A.M.; Domingues, P.; Calado, R.; et al. Valorization of lipids from Gracilaria sp. through lipidomics and decoding of antiproliferative and anti-Inflammatory activity. Mar. Drugs 2017, 15, 62. [CrossRef]

18. Cleaver, G.; Bullock, S. Development in ELSD technology to improve sensitivity and linearity of response over a wider dynamic range. Chromatogr. Today 2015, 8, 38-41. 
19. Surget, G.; Le Lann, K.; Delebecq, G.; Kervarec, N.; Donval, A.; Poullaouec, M.A.; Bihannic, I.; Poupart, N.; Stiger-Pouvreau, V. Seasonal phenology and metabolomics of the introduced red macroalga Gracilaria vermiculophylla, monitored in the Bay of Brest (France). J. Appl. Phycol. 2017, 29, 2651-2666. [CrossRef]

20. Kumari, P.; Kumar, M.; Gupta, V.; Reddy, C.R.K.; Jha, B. Tropical marine macroalgae as potential sources of nutritionally important PUFAs. Food Chem. 2010, 120, 749-757. [CrossRef]

21. Imbs, A.B.; Latyshev, N.A.; Svetashev, V.I.; Skriptsova, A.V.; Le, T.T.; Pham, M.Q.; Pham, L.Q. Distribution of polyunsaturated fatty acids in red algae of the genus Gracilaria, a promising source of prostaglandins. Russ. J. Mar. Biol. 2012, 38, 339-345. [CrossRef]

22. Norziah, M.H.; Ching, C.Y. Nutritional composition of edible seaweed Gracilaria changgi. Food Chem. 2000, 68, 69-76. [CrossRef]

23. Bhaskar, N.; Kinami, T.; Miyashita, K.; Park, S.B.; Endo, Y.; Fujimoto, K. Occurrence of conjugated polyenoic fatty acids in seaweeds from the Indian Ocean. Z. Naturforsch. C Biosci. 2004, 59, 310-314. [CrossRef]

24. Ohlrogge, J.; Browse, J. Lipid biosynthesis. Plant Cell 1995, 7, 957-970. [CrossRef] [PubMed]

25. Honda, M.; Kashima, A.; Takahashi, K.; Itabashi, Y. Molecular species of digalactosyldiacylglycerols in the brown alga Sargassum yezoense. Nippon Suisan Gakkaishi 2009, 75, 1061-1069. [CrossRef]

26. Itabashi, Y.; Kuksis, A.; Marai, L.; Takagi, T. HPLC resolution of diacylglycerol moieties of natural triacylglycerols on a chiral phase consisting of bonded (R)-(+)-1-(1-naphthyl) ethylamine. J. Lipid Res. 1990, 31, 1711-1717. [PubMed]

27. Itabashi, Y. Chiral-phase HPLC of glycerolipids. In HPLC in Acyl Lipids; Lin, J.-T., McKeon, T.A., Eds.; HNB Publishing: New York, NY, USA, 2005; pp. 167-198.

28. Itabashi, Y. Reverse isomers of glycoglycerolipids in marine red algae. In Proceedings of the 3rd Japan-Korea Joint Seminar on Fisheries Sciences, Jinju/Tongyeong, Korea, 15-16 December 2003; pp. 161-163.

29. Cho, S.H.; Thompson, G.A. On the metabolic relationships between monogalactosyldiacylglycerol and digalactosyldiacylglycerol molecular species in Dunaliella salina. J. Biol. Chem. 1987, 262, 7586-7593. [PubMed]

30. Ohta, H.; Awai, K.; Takamiya, K. Glyceroglycolipids of photosynthetic organisms-Their biosynthesis and evolutionary origin. Trends Glycosci. Glycotechnol. 2000, 12, 241-253. [CrossRef]

31. Somerville, C.; Browse, J. Plant lipids: Metabolism, mutants, and membranes. Science 1991, $252,80-87$. [CrossRef]

32. Bligh, E.G.; Dyer, W.J. A rapid method of total lipid extraction and purification. Can. J. Biochem. Physiol. 1959, 37, 911-917. [CrossRef]

33. Sugawara, T.; Miyazawa, T. Separation and determination of glycolipids from edible plant sources by high-performance liquid chromatography and evaporative light-scattering detection. Lipids 1999, 34, 1231-1237. [CrossRef]

34. Yunoki, K.; Sato, M.; Seki, K.; Ohkubo, T.; Tanaka, Y.; Ohnishi, M. Simultaneous quantification of plant glyceroglycolipids including sulfoquinovosyldiacylglycerol by HPLC-ELSD with binary gradient elution. Lipids 2009, 44, 77-83. [CrossRef] [PubMed]

35. Christie, W.W.; Han, X. Preparation of derivatives of fatty acids. In Lipid Analysis, 4th ed.; The Oily Press: Bridgwater, UK, 2010; pp. 145-158.

36. Takagi, T.; Asahi, M.; Itabashi, Y. Fatty acid composition of twelve algae from Japanese waters. J. Jpn. Oil Chem. Soc. 1985, 34, 1008-1012. [CrossRef]

37. Heinze, F.J.; Linscheid, M.; Heinz, E. Release of diacylglycerol moieties from various glycosyl diacylglycerols. Anal. Biochem. 1984, 139, 126-133. [CrossRef]

38. Hashidate, T.; Itabashi, Y. Electrospray ionization mass spectrometry of regioisomeric 1,2-diacylglycerols. Bunseki Kagaku 2005, 54, 807-816. [CrossRef]

(C) 2019 by the authors. Licensee MDPI, Basel, Switzerland. This article is an open access article distributed under the terms and conditions of the Creative Commons Attribution (CC BY) license (http:/ / creativecommons.org/licenses/by/4.0/). 